\title{
Exame Nacional do Ensino Médio e acesso de estudantes surdos ao Ensino Superior Brasileiro
}

Diléia Ap. Martins* , Cristina Broglia Feitosa Lacerda * * http://dx.doi.org/10.1590/0103-7307201507804

\section{Resumo}

Este trabalho apresenta as primeiras aproximações relativas à pesquisa "Acessibilidade e Exame Nacional do Ensino Médio: desafios para a escolarização de estudantes surdos", inserida no programa Observatório em Educação (Obeduc), Projeto Acessibilidade no Ensino Superior. Investiga dados oficiais publicados pelo Instituto Nacional de Estudos e Pesquisas (Inep), referentes ao aumento progressivo do número de matrículas de estudantes surdos em Instituições de Ensino Superior (IES). Analisa questões relativas à nota obtida por esses estudantes, ao se submeterem ao Exame Nacional do Ensino Médio (Enem), e o uso dessa nota para ingressarem em universidades brasileiras. Os dados analisados, no presente artigo, indicam discrepância de desempenho de estudantes sem deficiência, quando comparados aos estudantes surdos.

Palavras-chave: Enem, acesso ao Ensino Superior, surdos

* Docente do Departamento de Psicologia, Grupo de Pesquisa Abordagem Bilíngue e Surdez. Universidade Federal de São Carlos- UFSCar, São Carlos, São Paulo, Brasil. dileiamartins@gmail.com

* * Coordenadora do Programa de Pós-Graduação em Educação Especial- PPGEEs, Universidade Federal de São Carlos (UFSCar). cristinalacerda@uol.com.br 


\title{
Examination of high school students and national deaf access to higher education brazilian
}

\begin{abstract}
Based on the results obtained by deaf students in the National Secondary Education Examination (ENEM), and on official statistics on the number of deaf students in higher education, this article argues that the underrepresentation of deaf students in higher education derives at least in part from the inadequate conditions of accessibility that characterize the exam. It discusses the steps that should be taken by the federal government in order to overcome this situation.
\end{abstract}

Keywords: : ENEM, access to higher education, deaf students 


\section{Introdução}

A melhoria das condições de acessibilidade para estudantes surdos está relacionada às políticas educacionais e à gestão do poder público, que têm se organizado em meio às diferentes interpretações da Lei no 10.436 , de 24 de abril de 2002, que dispõe sobre a língua brasileira de sinais (Libras), e do Decreto $n^{0}-5.626$, de 22 de dezembro de 2005, que a regulamenta.

As orientações legais que subsidiam as ações direcionadas à acessibilidade de pessoas surdas a processos seletivos e de avaliação de toda ordem incluem o uso da língua de sinais e destacam a necessária presença de intérpretes de Libras, além de definir critérios flexíveis para a correção de redação e provas escritas (já que a pessoa surda é considerada usuária do português como segunda língua), e de oferecer apoio pedagógico direcionado à sua necessidade, acesso aos materiais didáticos e adequação da infraestrutura com vista à superação de todo tipo de barreira.

Os indicativos acerca da acessibilidade podem ser vistos como o reflexo de marcos históricos relacionados à pessoa com deficiência, tais como a Conferência Mundial de Jomtien, Tailândia (Unesco, 1990) e a Conferência Mundial sobre Necessidades Educativas Especiais (Unesco, 1994), que representaram um período de reformulação do conceito de deficiência e da postura da sociedade diante da presença desses sujeitos.

Resultado desse processo, a Declaração de Salamanca propôs aos Estados a garantia da educação de pessoas com deficiências como parte integrante do sistema educacional. A ideia defendida no texto da declaração é a de que toda criança tem direito fundamental à educação e à oportunidade de atingir e manter o nível adequado de aprendizagem.

Sob a influência de tais documentos, no Brasil, o novo texto da Lei de Diretrizes e Bases para Educação Nacional (LDBEN - 9394/96) assegurou o ensino de pessoas com deficiência, retomando elementos presentes na Constituição de 1988, ao reafirmar a necessidade de expandir o acesso desses sujeitos ao ensino comum, propondo que o ensino desse público ocorra prioritariamente na rede regular.

É a partir do final da década de 80 do século passado que o sistema de avaliação brasileiro vem sendo modificado, adotando medidas destinadas à melhoria da qualidade na educação. Considerando as avaliações utilizadas para essa finalidade, segundo Silva (2010), em 1988, houve uma primeira tentativa de aplicação do então criado Sistema Nacional de Avaliação do Ensino Público de 1ํGrau (Saep/MEC) nos estados do Paraná e Rio Grande do Norte e, em 1990, o primeiro ciclo do Sistema Na- 
cional de Avaliação da Educação Básica (Saeb). Em 2005, após um longo trabalho de aperfeiçoamento, é planejada a Prova Brasil, como um sistema definido de avaliação em larga escala de aplicação bianual.

A proposta de avaliação da qualidade da educação apoiada em provas aplicadas em larga escala tem perpassado todas as etapas e os níveis de ensino no País, com exceção da Educação Infantil. As avaliações têm sido organizadas pelo Instituto Nacional de Estudos e Pesquisas Educacionais Anísio Teixeira (Inep), órgão ligado ao Ministério da Educação (MEC). Com base na análise dos resultados alcançados nas avaliações que envolvem etapas e níveis da Educação Básica é que se obtém o Índice de Desenvolvimento da Educação Básica (Ideb). Esse índice é então usado pelo poder público como indicador para a verificação do cumprimento das metas fixadas no Termo de Adesão ao Compromisso “Todos pela Educação” do MEC (Inep, 2012).

O Ideb busca reunir num mesmo indicador dois conceitos implicados no campo da educação, de um lado o fluxo escolar e de outro as médias de desempenho nas avaliações. Nesse sentido, agrega ao foco pedagógico dos resultados das avaliações em larga escala a possibilidade de síntese dos resultados, visando traçar metas de qualidade educacional para os sistemas. A leitura dos dados referentes ao Ideb do Ensino Médio, observada em 2011, permite reconhecer que foi atingida a meta estabelecida pelo Ministério da Educação para aquele ano (valor 3.7).

Assim, para atender ao foco desta pesquisa, indaga-se o desempenho de estudantes surdos nessas avaliações, tendo em vista que a acessibilidade compõe um campo repleto de tensões, especificamente no que tange à pessoa surda, mediante a sua singularidade linguística. Para tal, a atenção será voltada para a nota obtida por esses estudantes no Exame Nacional do Ensino Médio (Enem), que compõe o sistema de avaliação da educação nacional.

Segundo Libâneo (2012), há na escola pública um dualismo perverso instituído por acordos internacionais e soluções amparadas em insumos, conjuntos, ciclos de escolarização, escola em tempo integral, entre outros, em detrimento do cuidado com fatores intraescolares. A escola pública adota esses mecanismos, consolidando, assim, uma visão de que o espaço escolar deve dispor de respeito à diferença numa dimensão integracionista, levando a educação escolar a associar-se mais a um local de encontro e partilha do que de aprendizagem.

Tratando os resultados das avaliações educacionais, Galuch e Sforni (2009) mencionam o mau desempenho em língua portuguesa apresentado pelos alunos brasi- 
leiros na avaliação realizada pelo Saeb. A análise de textos escritos produzidos por crianças em idade escolar revela o mau uso das regras gramaticais e ortográficas por alunos matriculados já nos anos finais. Os frutos de um modelo escolar, fundamentado em uma visão de educação integracionista, para respeito às diferenças e à socialização, têm apresentado problemas.

Essa situação se impõe de modo ainda mais contundente à criança surda, cuja educação escolar esteve caracterizada como um processo incapaz de proporcionar-lhe o desenvolvimento de formas superiores de pensamento. A maior parte das crianças, pela escassez de recursos para a efetivação do acesso à escolarização, tem se submetido a mera inserção na escola para convivência escolar e, mesmo diante dessas condições limitadas para o desenvolvimento escolar, passa, assim como os demais, pelos modelos avaliativos impostos a todos.

Cabe então destacar aqui questões relativas ao Exame Nacional do Ensino Médio (Enem). Criado em 1998, com o objetivo de avaliar o desempenho do estudante ao fim da escolaridade básica, passou a ser utilizado como critério de seleção para os estudantes que pretendiam concorrer a bolsa no Programa Universidade para Todos (ProUni). É determinado por uma concepção construtivista, e suas provas são elaboradas partindo do foco na resolução de problemas (Macedo, 2005).

Atualmente, a nota alcançada pelo estudante após submeter-se ao Enem pode ser utilizada também para ingresso em cursos superiores, de acordo com as regras de cada Instituição de Ensino Superior (IES). No que tange ao acesso de pessoas surdas a esse instrumento avaliativo, consideram-se as normas já existentes, entre elas o Aviso Circular no 277/MEC, publicado em 08 de maio de 1996, que propõe orientações aos reitores, com vistas à eliminação de barreiras ao ingresso das pessoas com deficiência ao Ensino Superior e, dentre elas, as pessoas surdas, sugerindo a presença de intérprete de Libras no processo de avaliação e a flexibilidade nos critérios de correção da redação e das provas discursivas dos candidatos com deficiência auditiva. Com relação ao último item, o Aviso Circular propõe que seja dada prioridade ao aspecto semântico da mensagem sobre o aspecto formal e/ou que sejam adotados outros mecanismos de avaliação da sua linguagem em substituição à prova de redação.

0 Decreto $n^{\circ} \mathbf{5 . 6 2 6}$, de 22 de dezembro de 2005 , possui um capítulo que trata especificamente do uso e da difusão da Libras e da língua portuguesa para o acesso das pessoas surdas à educação. Reforça a noção de garantia do direito ao intérprete de Libras, como também propõe a adoção de "mecanismos de avaliação coerentes com 
aprendizado de segunda língua [...] e de mecanismos alternativos para a avaliação" (p. 1). A oferta de educação bilíngue acessível a pessoas fluentes na língua de sinais é vista como um desafio diante de um modelo educacional historicamente delimitado por práticas pouco acessíveis (Lacerda, Albres, \& Drago, 2013) e de um cenário político de confronto de concepções acerca do processo de escolarização de pessoas surdas (Lodi, 2013).

O estudante surdo que chega ao fim da trajetória escolar na Educação Básica precisará ainda submeter-se a um instrumento avaliativo para ingresso na universidade, o vestibular ou o Enem, sendo que o primeiro é a forma tradicional de ingresso e vem perdendo cada vez mais espaço para o segundo, um instrumento que visa avaliar competências e habilidades do estudante ao término desse ciclo.

\section{Ampliação do acesso ao ensino no Brasil}

Entre os anos 2003 e 2008, em meio a uma conjuntura econômica mundial favorável, instaurava-se, no Brasil, o primeiro mandato do presidente Luís Inácio Lula da Silva. Ao longo de seu governo, foram implementados diversos programas sociais, tais como: Bolsa Família; Fome Zero; Primeiro Emprego; diminuição da mortalidade infantil e combate à escravidão, sendo que a maior parte deles possuía um envolvimento direto com a educação. Por exemplo, o Bolsa Família, criado por meio do Decreto n. 5.209 de 17, de setembro de 2004, tinha por finalidade transferir renda direta do governo para as famílias em situação de extrema miséria, e uma das exigências principais era que todos os membros da família em idade escolar deveriam frequentar a escola - a ausência à escola implicava perda da bolsa. Tratava-se da ampliação e da reformulação do programa Bolsa Escola, criado no governo de Fernando Henrique Cardoso (FHC). Amostras coletadas pelo Instituto Brasileiro de Geografia e Estatística (IBGE), quando da realização do recenseamento, vêm demonstrando que tais programas e políticas alteraram as condições de vida de seus beneficiários, melhorando sua renda e possibilitando a ampliação do acesso a produtos e serviços (IBGE, 2010).

No governo FHC, conforme assumido por Paulo Renato de Souza (então ministro da Educação), no Aviso Circular nํㅜ 277 , não havia sequer o acompanhamento estatístico de dados referentes ao número de estudantes com deficiência matriculados e concluintes da Educação Básica, muito menos dos candidatos matriculados na Educação Superior, indicando que havia um desinteresse por este tema e/ou que não se problematizava a adoção de uma proposta educacional institucionalizada em detri- 
mento de ações para transformação da escola comum e da educação pública.

No ano de 2006, foi publicado o documento Números da Educação Especial no Brasil, que contempla um diagnóstico quantitativo da educação especial no País. 0 documento indica que houve aumento do número de estudantes com deficiência matriculados na escola comum pública entre os anos 1998 e 2006. Menciona que, nesse período, houve crescimento de $640 \%$ das matrículas em escolas comuns e de $28 \%$ em escolas e classes especiais.

Segundo esse mesmo documento, com relação às condições de infraestrutura nas escolas públicas, um ano antes da posse do presidente Lula, em 2002, havia 5.016 escolas públicas com sanitários adequados e 3.755 escolas públicas com dependências e vias adequadas aos "alunos com necessidades educacionais especiais". Em 2006, os números eram 12.684 e 8.888 , respectivamente. Na Educação Superior, no ano de 2003, início do mandato do presidente Lula, havia um total de 5.078 matrículas de estudantes com deficiência em IES, sendo 1.373 em IES públicas e 3.705 em IES privadas.

A proposta de governo, que assumia o desafio de construir um sistema educacional inclusivo no País, contemplava a adoção de ações voltadas para a inclusão escolar dos estudantes com deficiência, transtornos globais de desenvolvimento e altas habilidades. De acordo com a síntese do balanço elaborado pelo governo federal' segundo discurso do próprio ex-presidente Lula, o objetivo foi

comparar o meu programa de governo, os compromissos que assumi, com as coisas que eu realizei. Eu quero entregar ao meu sucessor, à imprensa, aos sindicalistas, às entidades empresariais ... cada coisa que nós fizemos, cada obra, cada projeto, cada investimento, que é para não apagar a memória (p. 139).

Compõe esse balanço um destaque do governo federal à criação, em 2003, do Programa Educação Inclusiva: Direito à Diversidade². Esse Programa apresentou os conceitos utilizados no censo escolar referentes às tipologias de deficiência e fomentou a abertura de um debate resultante na elaboração e no lançamento, em 2008, da nova Política da Educação Especial na perspectiva da educação

1. 0 balanço completo pode ser acessado pelo site: http://www.balancodegoverno.presidencia.gov.br/.

2. O Ministério da Educação, por meio da Secretaria de Educação Especial, desenvolve o Programa Educação Inclusiva: Direito à Diversidade em todos os estados e Distrito Federal, envolvendo 106 municípios-polo que atuam como multiplicadores para municípios da sua área de abrangência, compreendendo atualmente 1.869 municípios. 0 objetivo é a formação de gestores e educadores para efetivar a transformação dos sistemas educacionais em sistemas educacionais inclusivos, tendo como princípio a garantia do direito de acesso e permanência, com qualidade, dos alunos com necessidades educacionais especiais nas escolas regulares. 
inclusiva, que retomou todo o processo histórico da educação da pessoa com deficiência com base em acordos internacionais e em leis nacionais.

O documento menciona ainda que, na Educação Superior, devem ser efetivadas ações que promovam o acesso, a permanência e a participação dos estudantes com deficiência, envolvendo o planejamento e a organização de recursos e serviços para a promoção da acessibilidade arquitetônica, nas comunicações, nos sistemas de informação e nos materiais didáticos e pedagógicos, que devem ser disponibilizados nos processos seletivos e no desenvolvimento de todas as atividades que envolvam o ensino, a pesquisa e a extensão.

Por meio do Decreto 6.571/20084, foi instituído, no âmbito do Fundo do Desenvolvimento da Educação Básica (Fundeb), o financiamento do Atendimento Educacional Especializado (AEE), e o trabalho desempenhado pela educação especial passou a centralizar-se em recursos e serviços - "conjunto de atividades, recursos de acessibilidade e pedagógicos organizados institucionalmente, prestados de forma complementar ou suplementar à formação dos alunos no ensino regular” (p. 1). Nessa linha de trabalho, os programas Escola Acessível e Sala de Recursos Multifuncionais promoveram a adaptação e a adequação de prédios e salas escolares para atender pessoas com deficiência e mobilidade reduzida, disponibilizando mobiliário adequado aos alunos público-alvo da educação especial. Entre 2008 e 2009, 11.205 escolas implementaram ações de acessibilidade.

Em complemento, a resolução CNE/CEB 4/2009, que instituiu as Diretrizes operacionais para o $A E E$ na Educação Básica apresenta como lócus do AEE a Sala de Recursos Multifuncionais (SRM). Assim, a educação especial passa a caracterizar-se pelo trabalho realizado na escola comum sob a perspectiva inclusiva, com serviços e atendimentos da educação especial. Em face desse modo característico de funcionamento da educação especial, tendo por base a frequência do aluno à escola comum e, no contraturno escolar, à SRM, indaga-se quanto e como esse atendimento contemplaria, de fato, as necessidades dos estudantes (Lodi, 2014).

Segundo Garcia e Michels (2009), ao longo do governo de Lula, a Política Nacional de Educação Especial ganhou novos contornos, de modo singular, pela implementa-

3. 0 documento oficial da Política foi elaborado pelo Grupo de Trabalho, nomeado pela Portaria Ministerial n- 555 , de 5 de junho de 2007, prorrogada pela Portaria $\mathrm{n}^{0} \mathbf{9 4 8}$, de o9 de outubro de 2007.

4. Esse decreto foi substituído pelo Decreto $\mathrm{n}^{0}-7.611$, de 17 de novembro de 2011. ção de três programas: 1) Programa de Implantação de Salas de Recursos Multifuncionais; 2) Programa Educação Inclusiva: Direito à Diversidade; 3) Programa Incluir. O primeiro, por representar o fortalecimento do processo de inclusão de es- 
tudantes com deficiência na escola comum de ensino regular pública. 0 segundo, por proporcionar formação aos gestores estaduais e municipais para expansão das ações do AEE. Pelo programa de implementação de SRM e pelo Decreto 6.571/2008, o lócus privilegiado do AEE continua sendo a complementação e a suplementação à educação regular. Tais programas representam atos concretos da gestão política governamental, que resultaram na modificação direta do cenário da educação especial, em nível de Educação Básica no País.

No que tange à Educação Superior, o terceiro Programa, o Incluir, propõe ações que visam ao acesso de pessoas com deficiência às instituições federais e à garantia de condições de acessibilidade. Se, na Educação Básica, era possível identificar com clareza as opções disponíveis para estudantes com deficiência, na Educação Superior, somente em 2000, a extinta Secretaria de Educação Especial (SEESP/MEC) e a Secretaria de Ensino Superior (SESU/MEC) direcionaram às IES orientações específicas para adaptação dos recursos instrucionais, capacitação de recursos humanos e adequação de recursos físicos para os estudantes com deficiência, indicando que cada IES apresentasse um plano de implantação da acessibilidade, de modo a favorecer o acesso, o ingresso e a permanência desses estudantes no Ensino Superior. Em 2003, foi publicada a Portaria $n-3.284$, que estabelece normas para oferta de cursos superiores, reafirmando o compromisso formal das IES para com os estudantes com deficiência.

Somente em 2005, as universidades federais foram dotadas dos recursos do Incluir, que, desde sua criação, é executado por meio da parceria entre a Secretaria de Educação Superior (SESu) e a Secretaria de Educação Continuada, Alfabetização, Diversidade e Inclusão (SECADI), ambas do MEC. Essas secretarias divulgavam um edital público com dotação orçamentária para contemplar as universidades que propusessem ações com foco no público-alvo da educação especial. Com o intermédio do auxílio prestado pelo Programa Incluir, as IFES podiam então criar e consolidar núcleos de acessibilidade. Esses, por sua vez, ficavam responsáveis pela organização de ações institucionais para fomentar a inclusão de pessoas com deficiência, propiciar a eliminação de barreiras pedagógicas, arquitetônicas, comunicacionais e de informação, com vistas ao cumprimento dos requisitos legais relacionados à acessibilidade.

O programa, até 2010, disponibilizava recursos às universidades selecionadas de acordo com normas publicadas em edital. Em 2012, a seleção deixou de ocorrer, sendo então disponibilizada dotação orçamentária para cada universidade federal que já tivesse sido contemplada, com projeto aprovado, nos anos anteriores. Em 2013, 
foram alocados recursos diretamente para as Unidades Orçamentárias (UO) de 55 universidades federais. Atualmente, esses recursos vêm destacados nos orçamentos das IFES, para que sejam gastos com ações destinadas para esse público.

\section{Uma possível leitura dos indicadores educacionais}

Os dados do Censo da Educação Superior referentes ao ano 2011 revelam a existência de um total de 6.739.689 matrículas neste nível de ensino. Desse universo, de acordo com dados disponibilizados pelo Inep (conforme Tabela 1), 23.250 é o número absoluto de matrículas de pessoas com deficiência (PcD). Martins, Leite e Lacerda (2015) discutem a evolução do número de matrículas de pessoas com deficiência no Ensino Superior brasileiro.

Tabela 1 - Matrículas em IES: graduação presencial e a distância

\begin{tabular}{|c|c|c|c|c|c|c|c|c|c|}
\hline ANO & TOTAL & $\begin{array}{l}\text { PCD } \\
\text { FA(n) }\end{array}$ & $\begin{array}{l}\text { PCD } \\
\text { FR(\%) }\end{array}$ & $\begin{array}{l}\text { IES } \\
\text { PUBLICA }\end{array}$ & $\begin{array}{l}\text { PCD } \\
\text { FA(n) }\end{array}$ & $\begin{array}{l}\text { PCD } \\
\text { FR(\%) }\end{array}$ & $\begin{array}{l}\text { IES } \\
\text { PRIVADA }\end{array}$ & $\begin{array}{l}\text { PCD } \\
\text { FA(n) }\end{array}$ & $\begin{array}{l}\text { PCD } \\
\text { FR(\%) }\end{array}$ \\
\hline 2000 & 2694245 & 2173 & 0.08 & 887026 & 1135 & 0.13 & 1807219 & 1038 & 0.06 \\
\hline 2001 & 3030774 & 2898 & 0.10 & 939225 & 391 & 0.04 & 2091529 & 2507 & 0.12 \\
\hline 2002 & 3479913 & 2425 & 0.07 & 1051655 & 705 & 0.07 & 2428258 & 1720 & 0.07 \\
\hline 2003 & 3564628 & 5078 & 0.14 & 1136370 & 1373 & 0.12 & 2750652 & 3705 & 0.13 \\
\hline 2004 & 4163733 & 5395 & 0.13 & 1178328 & 1318 & 0.11 & 2985405 & 4077 & 0.14 \\
\hline 2005 & 4453156 & 6327 & 0.14 & 1192189 & 2080 & 0.17 & 3260967 & 4247 & 0.13 \\
\hline 2006 & 4676646 & 6960 & 0.15 & 1209304 & 1855 & 0.15 & 3467342 & 5105 & 0.15 \\
\hline 2007 & 4880381 & 6934 & 0.14 & 1240968 & 1390 & 0.11 & 3639413 & 5544 & 0.15 \\
\hline 2008 & 5080056 & 12015 & 0.24 & 1273965 & 1984 & 0.16 & 3806091 & 10031 & 0.26 \\
\hline 2009 & 5954021 & 20965 & 0.35 & 1523864 & 6598 & 0.43 & 4430157 & 14367 & 0.32 \\
\hline 2010 & 6379299 & 20287 & 0.32 & 1643298 & 6884 & 0.42 & 4736001 & 13403 & 0.28 \\
\hline 2011 & 6739689 & 23250 & 0.34 & 1773315 & 6531 & 0.37 & 4966374 & 16719 & 0.34 \\
\hline
\end{tabular}

Legenda: PcD - pessoa com deficiência; FA - frequência absoluta; FR - frequência relativa Fonte: MEC/INEP

Enquanto o número de matrículas de alunos sem deficiência aumentou 2,5 vezes aproximadamente entre os anos de 2000 e 2011, a evolução de matrículas de pessoas 
com deficiência foi maior que 10 vezes, no mesmo período. Essa evolução na matrícula de pessoas com deficiência parece indicar que os impactos das políticas públicas no campo da educação e da pessoa com deficiência favoreceram em alguma medida uma melhoria de condições para esse público.

O foco deste artigo centra-se no campo da surdez, e então cabe destacar a presença deste público do conjunto das pessoas com deficiência. Observa-se, na Tabela 2, que, para o ano de 2011, o número de matrículas de estudantes com surdez é de 1.582, e de estudantes com deficiência auditiva é de 4.078 .

Tabela 2 - Matrículas de estudantes com surdez e deficiência auditiva no Ensino Superior, Brasil (2011)

\begin{tabular}{|c|c|c|c|c|c|c|c|}
\hline ANO & TOTAL & $\begin{array}{c}\text { PcD FA } \\
(\mathrm{n})\end{array}$ & $\begin{array}{c}\text { PcD FR } \\
(\%)\end{array}$ & $\begin{array}{c}\text { SURDEZ } \\
\text { FA }(\mathrm{n})\end{array}$ & $\begin{array}{c}\text { SURDEZ } \\
\text { FR }(\%)\end{array}$ & $\begin{array}{c}\text { DA FA } \\
(\mathrm{n})\end{array}$ & $\begin{array}{c}\text { DA FR } \\
(\%)\end{array}$ \\
\hline 2011 & 67399689 & 23250 & 0.34 & 1582 & 0.02 & 4078 & 0.06 \\
\hline
\end{tabular}

Fonte: Inep (2011).

Conhecido o número de matrículas, buscou-se identificar, dentre os ingressantes no ano de 2011, aqueles com surdez e com deficiência auditiva, segundo os critérios de classificação oferecidos pelo Inep. Assim, foi possível constatar que o número total de ingressantes no ano de 2011 foi de 2.346.695 (em cursos presenciais e a distância), sendo 7.992 de PcD, e destes 495 eram estudantes com surdez e 1.465 com deficiência auditiva. A Tabela 3 mostra esses dados.

Tabela 3 - Ingressantes com surdez e deiciência auditiva no Ensino Superior , Brasil (2011) Fonte: Inep (2011).

\begin{tabular}{|c|c|c|c|c|c|c|c|}
\hline ANO & TOTAL & $\begin{array}{c}\text { PcD FA } \\
(\mathrm{n})\end{array}$ & $\begin{array}{c}\text { PcD FR } \\
(\%)\end{array}$ & $\begin{array}{c}\text { SURDEZ } \\
\text { FA (n) }\end{array}$ & $\begin{array}{c}\text { SURDEZ } \\
\text { FR }(\%)\end{array}$ & $\begin{array}{c}\text { DA FA } \\
(\mathrm{n})\end{array}$ & $\begin{array}{c}\text { DA FR } \\
(\%)\end{array}$ \\
\hline 2011 & 2346695 & 7992 & 0.34 & 495 & 0.02 & 1465 & 0.06 \\
\hline
\end{tabular}

Fonte: Inep (2011).

Assim, de acordo com a Tabela 3, as pessoas com surdez correspondem a $0.02 \%$ do total de ingressantes, e as pessoas com deficiência auditiva, a 0.06\% deste mesmo total. De acordo com o Censo da Educação Superior (2011), o ingresso pelo apro- 
veitamento da nota obtida no Enem 2011 corresponde ao total de 342.851, sendo que 2.325 eram estudantes com deficiência. Assim, dos estudantes com deficiência, apenas $0,10 \%$ ingressou com o uso da nota obtida no Exame.

Compreende-se, após a leitura desses dados, que um dos elementos determinantes para o baixo número de ingressantes em IES é a nota obtida pelo estudante ao submeter-se ao Enem. Nessa perspectiva, os dados relativos à proficiência (nota obtida) demonstram diferenças consideráveis, entre os estudantes com e sem deficiência, com relação ao processo de leitura e escrita, por exemplo.

Segundo o Inep (2012), a proficiência é calculada a partir do desempenho do participante na resolução das questões da prova.

Entretanto, o mínimo e o máximo em cada prova dependem somente das questões que compõem a prova e não de quem as responde. Apesar de as provas poderem apresentar mínimos e máximos diferentes, seus resultados são comparáveis, pois eles são todos calculados na mesma escala construída a partir de uma única matriz de competências (p. 12).

A equipe do Inep desenvolveu uma escala para cada uma destas áreas: Ciências Naturais, Ciências Humanas, Linguagens e Códigos e Matemática. A escala de proficiência é uma forma de estabelecer uma unidade de medida padrão do conhecimento. A nota é atribuída com base em uma escala de proficiência estabelecida por uma unidade de medida que conjuga um número a uma área do conhecimento em que 500 é o valor de referência.

A nota na escala pode assumir qualquer valor no conjunto dos números reais e essa nota está associada à complexidade da prova, constituída por itens/questões fáceis, medianas e difíceis. Assim se entende que a nota mínima não é zero e a nota máxima não é 1000, com base em números absolutos. Essa nota é calculada a partir de um modelo matemático da Teoria de Resposta ao Item (Tri), segundo o qual cada item é uma questão, e o cálculo da nota é realizado tendo em vista a consistência da resposta, conforme o grau de dificuldade de cada questão.

No Brasil, a Tri passou a ser utilizada pelo Saeb, em 1995; e, posteriormente, no Exame Nacional para Certificação de Competências de Jovens e Adultos (Encceja), na Prova Brasil; e, por último, no Enem. A análise proposta pela Tri parte do princípio de que, com base na nota, gera-se uma curva que mostra a relação entre a probabilidade de acerto, os parâmetros dos itens e a proficiência do respondente. A interpretação pedagógica atribuída ao desempenho do candidato o posiciona na escala, de acordo 
com os parâmetros curriculares e com a coerência pedagógica por ele demonstrada na realização do exame (Inep, 2012), como se pode observar no Quadro 1.

\section{Quadro 1 - Escala de proficiência na área do conhecimento}

Ciências Humanas - Valores pessoas sem deficiência.

\begin{tabular}{|c|c|}
\hline VALOR NA ESCALA & DESCRIÇÃo \\
\hline 500.0 & $\begin{array}{r}\text { Identificar a importância da contribuição do povo africano } \\
\text { para a formação cultural brasileira. }\end{array}$ \\
\hline 493.8 & $\begin{array}{r}\text { Identificar relações de sustentabilidade entre produção } \\
\text { e preservação ambiental nos núcleos urbanos. }\end{array}$ \\
\hline 485.0 & $\begin{array}{r}\text { Identificar em representação cartográfica } \\
\text { a distribuição de bovinos no bioma amazônico. }\end{array}$ \\
\hline 481.2 & $\begin{array}{r}\text { Identificar em representação cartográfica as redes de influência } \\
\text { das grandes potências econômicas no cenário mundial. }\end{array}$ \\
\hline 473.1 & $\begin{array}{r}\text { Identificar a presença do trabalho escravo africano } \\
\text { na atividade açucareira na América portuguesa. }\end{array}$ \\
\hline 468.8 & $\begin{array}{r}\text { Reconhecer as diferenças entre processos } \\
\text { de transformação de matérias-primas. }\end{array}$ \\
\hline 464.3 & $\begin{array}{r}\text { Reconhecer a importância dos movimentos sociais no processo } \\
\text { de construção das práticas democráticas no Brasil. }\end{array}$ \\
\hline
\end{tabular}

Fonte: Inep (2011).

Os dados apresentados no Quadro 2 situam-se entre os valores da escala e a descrição dos conhecimentos relacionados à nota obtida pelos participantes sem deficiência na área do conhecimento Ciências Humanas.

A nota numericamente atribuída ao conhecimento da área Ciências Humanas serve de parâmetro para mensurar o quanto o estudante que se submete ao Enem se apropriou desse saber, ou o quanto foi capaz de estabelecer conexões entre o currículo escolar e sua vivência cotidiana. De acordo com a escala elaborada pelo Inep, o valor 481.2 corresponde a “Identificar em representação cartográfica as redes de 
influência das grandes potências econômicas no cenário mundial”, e o valor 473.1 a “Identificar a presença do trabalho escravo africano na atividade açucareira na América portuguesa”. A média nacional, 478,11, se enquadraria entre esses dois valores, e isso quer dizer que a média obtida por esses estudantes revela o quanto este grupo foi capaz de associar o saber curricular e a vivência diária ao estabelecido pelas diretrizes do Inep para elaboração do Enem naquele período-ano.

O Quadro 2 compara o desempenho dos estudantes com surdez e deficiência auditiva e os sem deficiência, no ano de 2011, nas diferentes áreas.

Quadro 2 - Desempenho dos estudantes com surdez e com deficiência auditiva e os sem deficiência no Enem 2011

\begin{tabular}{|c|c|c|c|c|c|}
\cline { 2 - 6 } \multicolumn{1}{c|}{} & $\begin{array}{c}\text { NOTA } \\
\text { CIÊNCIAS } \\
\text { NATURAIS }\end{array}$ & $\begin{array}{c}\text { NOTA } \\
\text { CIÊNCIAS } \\
\text { HUMANAS }\end{array}$ & $\begin{array}{c}\text { NOTA } \\
\text { LINGUAGEM } \\
\text { E CÓDIGOS }\end{array}$ & $\begin{array}{c}\text { NOTA } \\
\text { MATEMÁTICA }\end{array}$ & REDAÇÃO \\
\hline SURDEZ & 367,055 & 360,821 & 422,328 & 430,680 & 191,540 \\
\hline $\begin{array}{c}\text { DEFICIÊNCIA } \\
\text { AUDITIVA }\end{array}$ & 390,926 & 388,034 & 445,228 & 445,415 & 266,097 \\
\hline $\begin{array}{c}\text { SEM } \\
\text { DEFICIÊNCIA }\end{array}$ & 466,571 & 478,119 & 520,987 & 517,393 & 519,247 \\
\hline
\end{tabular}

Fonte: Inep (2011).

Para ser considerado proficiente, o candidato deveria dominar as habilidades avaliadas nas questões na escala elaborada pelo Inep, correspondente aos saberes de determinada área do conhecimento, sendo o valor mínimo de 500. Para o cálculo da nota pela Tri, almeja-se que os participantes que acertaram questões difíceis acertem também questões fáceis, pois se entende que a aquisição do conhecimento ocorre de forma cumulativa, sendo as habilidades mais simples requeridas pelo domínio de habilidades mais complexas (Inep/Enem, 2012, p. 19).

Na escala utilizada pelo Enem, identifica-se o baixo desempenho de participantes com surdez que, no ano 2011, obtiveram a proficiência 360,82; como se observa no Quadro 3 a seguir: 


\section{Quadro 3 - Proficiência dos participantes com surdez no Enem. Área do conhecimento Ciências Humanas}

\begin{tabular}{|c|c|}
\hline VALOR NA ESCALA & DESCRIÇÃO \\
\hline 464.3 & $\begin{array}{l}\text { Reconhecer a importância dos movimentos sociais no processo } \\
\text { de construção das práticas democráticas no Brasil. }\end{array}$ \\
\hline 456.2 & $\begin{array}{l}\text { Reconhecer consequências da deposição incorreta } \\
\text { de resíduos em áreas urbanas. }\end{array}$ \\
\hline $\mathrm{C}^{8}$ & $\begin{array}{l}\text { Relacionar o processo de interação entre o desenvolvimento } \\
\text { científico e a produção artística no período renascentista. }\end{array}$ \\
\hline 446.4 & Reconhecer as diretrizes da organização sindical no Estado Novo. \\
\hline 446.2 & $\begin{array}{l}\text { Identificar as reivindicações da vertente pacifista do movimento } \\
\text { negro por direitos civis nos EUA em meados do século XX. }\end{array}$ \\
\hline C & $\begin{array}{l}\text { Identificar o uso da técnica e da tecnologia para alterar a lógica } \\
\text { prevalecente do consumo de água no mundo contemporâneo. }\end{array}$ \\
\hline 431.2 & $\begin{array}{l}\text { Reconhecer características presentes nas favelas que levam } \\
\text { aos problemas de desordenamento territorial. }\end{array}$ \\
\hline 397.1 & $\begin{array}{l}\text { Reconhecer a necessidade do desenvolvimento de tecnologias } \\
\text { ao longo do processo de adaptação humana ao meio natural. }\end{array}$ \\
\hline 346.6 & $\begin{array}{l}\text { Relacionar o aumento da poluição nas grandes metrópoles } \\
\text { com a diminuição da expectativa de vida da população. }\end{array}$ \\
\hline
\end{tabular}

Fonte: Inep (2012).

Com base na leitura dos dados expostos, identifica-se que a média nacional na área Ciências Humanas alcançada por pessoas sem deficiência corresponde a 478,11, enquanto a média obtida por pessoas com surdez e deficiência auditiva é equivalente a 360,82. Pode-se aferir que, embora tanto os participantes com deficiência quanto os que não a têm (nota 478,11) não tenham atingido a média esperada - 500 pontos - na área Ciências Humanas, o desempenho de estudantes com surdez ficou abaixo da média nacional. 


\section{Considerações finais}

O modo como se tem conduzido a avaliação da qualidade da Educação Básica brasileira instiga o aprofundamento de análises e pesquisas sobre o alcance dessa avaliação, sobre a metodologia empregada e sobre seu impacto nas políticas públicas. Neste artigo, mais especificamente, buscou-se desvelar aspectos relacionados ao Enem. Estudantes concluintes do Ensino Médio não alcançaram a nota compatível com a média esperada - 500 pontos. A média nacional dos estudantes é 478,11 pontos e a situação torna-se mais crítica quando o foco se dirige para os estudantes surdos, cuja média é de 360,82 pontos. Esse resultado pode indicar que a educação ofertada a este público não tem alcançado a qualidade esperada, ou seja, essa população não tem sido contemplada com uma educação que favoreça sua aprendizagem dentro dos parâmetros previstos para este nível de ensino.

Um exame organizado de modo a instigar o participante a estabelecer conexões entre o conteúdo curricular e o saber vivido em seu cotidiano, tendo por base questões sistematizadas a partir dos saberes mais simples até os mais complexos, exige uma leitura de mundo que se revela pouco favorecida pelo processo educacional inclusivo vigente, quando consideradas as médias apresentadas pelos estudantes surdos.

Mediante as condições explicitadas, poucos são aqueles que conseguem, com uso da nota obtida no Enem, ingressar em cursos superiores. Os dados analisados no presente artigo mostram a discrepância na preparação educacional de estudantes sem deficiência, quando comparados aos estudantes surdos.

Cabe indagar se os problemas estão somente na preparação desses estudantes durante o Ensino Médio ou se a própria forma de apresentação do exame compromete o seu desempenho. Há indicativos recentes de que, nos processos seletivos para ingresso e permanência nos cursos oferecidos pelas instituições de Ensino Superior e de educação profissional e tecnológica, públicas e privadas, se deve adotar a tradução completa do edital e de suas retificações em Libras (Brasil, 2015). Com a adoção dessa medida, o número de interessados e aprovados nos exames poderá crescer, já que as condições de acessibilidade serão mais favoráveis. Contudo permanece a indagação sobre a qualidade da educação ofertada a esses estudantes, e os modos como as avaliações de larga escala podem ser efetivamente sensíveis a essa qualidade. 


\section{Referências bibliográficas}

Galuch, M. T. B., \& Sforni, M. S. de F. (2009, janeiro/abril). Aprendizagem conceitual e apropriação da linguagem escrita: contribuições da teoria histórico cultural. Estudos em avaliação educacional, 20 (42), 111-124.

Garcia, R. M. C., \& Michels, M. H. (2009). A política de educação especial no Brasil (1991-2011): uma análise da produção do GT15 Educação Especial da Anped. Revista Brasileira de Educação Especial, 17, 105-124.

IBGE. Instituto Brasileiro de Geografia e Estatística. (2010) Censo Demográfico. Retirado em 10 de dezembro de 2013, de 〈http://www.ibge.gov.br/home/ estatistica/populacao/cens0200o/default.shtm〉.

Instituto Nacional de Estudos e Pesquisas Educacionais Anísio Teixeira. (2012). Censo da Educação Superior: 2011. Resumo técnico. Brasília: Instituto Nacional de Estudos e Pesquisas Educacionais Anísio Teixeira.

Instituto Nacional de Estudos e Pesquisas Educacionais Anísio Teixeira. (2013). Censo da Educação Superior: 2012. Resumo técnico. Brasília: Instituto Nacional de Estudos e Pesquisas Educacionais Anísio Teixeira.

Lacerda, C. B. F. de, Albres, N. de A., \& Drago, S. L. dos S. (2013, março). Política para uma educação bilíngue e inclusiva a alunos surdos no município de São Paulo. Educação e Pesquisa, 39(1), 65-80. ISSN 1517-9702.

Libâneo, J. C. (2012, março). O dualismo perverso da escola pública brasileira: escola do conhecimento para os ricos, escola do acolhimento social para os pobres. Educação e Pesquisa, 38(1), 13-28. Retirado em 02 de novembro de 2013, de 〈http://www.scielo.br/ scielo.php?script=sci_arttext\&pid=S1517 97022012000100002\&lng=en\&nrm=iso〉. http://dx.doi.org/10.1590/S151797022011005000001.

Lodi, A. C. B. (2013). Educação bilíngue para surdos e inclusão segundo a Política Nacional de Educação Especial e o Decreto no 5.626/05. Educação e Pesquisa. [online], 39(1), 49-63. ISSN 1517-9702. http://dx.doi.org/10.1590/S151797022013000100004 .

Lodi, A. C. B. (2014). Declaraciones de UNESCO, educación de sordos y educación inclusiva: un analisis de la politica nacional de educación de Brasil. Psicología, Conocimiento y Sociedad, 4, 261-294.

Macedo, L. (2005). Competências e habilidades: elementos para uma reflexão pedagógica. In J. S. Moraes (Org.), Exame Nacional do Ensino Médio (ENEM): Fundamentação teórico-metodológica (pp. 13-28). Brasília: O Instituto (Inep/ MEC). 
Martins, D. A, Leite, L. P., \& Lacerda, C. B. F de. (2015, out./dez.). Políticas públicas para acesso de pessoas com deficiência ao ensino superior brasileiro: uma análise de indicadores educacionais. Ensaio, 23(89), 1-31.

Organizações das Nações Unidas para a Educação, Ciência e Cultura. Unesco. (1990). Declaração Mundial sobre Educação Para Todos (Conferência de Jomtien). Tailândia: Unesco.

Organizações das Nações Unidas para a Educação, Ciência e Cultura. Unesco. (1994). Declaração de Salamanca e linha de ação sobre necessidades educativas especiais. Salamanca: Unesco.

Silva, I. F. (2010, set./dez). O sistema nacional de avaliação: características, dispositivos legais e resultados. Estudos em Avaliação Educacional, 21(47), 427448.

\section{Legislação}

Constituição da República Federativa do Brasil, de 5 de outubro de 1988. Organização do texto por Juarez de Oliveira. 4. ed. São Paulo: Saraiva. 168 p. (Série Legislação Brasileira).

Aviso Circular no 277. Brasília, DF, o8 de maio de 1996.

Lei no 9.394/96. Lei de Diretrizes e Bases da Educação Nacional. Brasília, DF, 20 dezembro de 1996.

Lei $n$ ㅇ 10.098 , de 19 de dezembro de 2000. Estabelece normas gerais e critérios básicos para a promoção da acessibilidade das pessoas portadoras de deficiência ou com mobilidade reduzida, e dá outras providências. Diário Oficial [da] República Federativa do Brasil, Brasília, DF.

Lei $n^{\circ}$ 10.436, de 24 de abril de 2002. Dispõe sobre a Língua Brasileira de Sinais Libras e dá outras providências. Diário Oficial [da] República Federativa do Brasil, Brasília, DF.

Portaria $n^{0} 3.284$ de. 07 de novembro de 2003. Dispõe sobre requisitos de acessibilidade de pessoas portadoras de deficiências, para instruir os processos de autorização e de reconhecimento de cursos, e de credenciamento de instituições. Secretaria de Educação Especial.

Decreto n- 5.209, de 17 de setembro de 2004. Regulamenta a Lei no10.836, de 9 de janeiro de 2004, que cria o Programa Bolsa Família, e dá outras providências. Diário Oficial [da] República Federativa do Brasil, Brasília, DF. 
Decreto 5.626, de dezembro de 2005. Regulamenta a Lei no 10.436, de 24 de abril de 2002, que dispõe sobre a Língua Brasileira de Sinais - Libras, e o art. 18 da Lei no 10.098, de 19 de dezembro de 2000. Diário Oficial [da] República Federativa do Brasil, Brasília, DF.

Decreto 6.571. Dispõe sobre o atendimento educacional especializado, regulamenta o parágrafo único do art. 60 da Lei $n^{\circ}$ 9.394, de 20 de dezembro de 1996, e acrescenta dispositivo ao Decreto $\mathrm{n}^{\circ} 6.253$, de 13 de novembro de 2007. Diário Oficial [da] República Federativa do Brasil, Brasília, DF.

Política Nacional de Educação Especial na Perspectiva da Educação Inclusiva.

Documento elaborado pelo Grupo de Trabalho nomeado pela Portaria Ministerial $\mathrm{n}$ 555 , de 5 de junho de 2007, prorrogada pela Portaria $\mathrm{n}-948$, de 09 de outubro de 2007.MEC/SEESP

Resolução $n^{\circ}$ 4, de 2 outubro de 2009. Institui diretrizes operacionais para 0 atendimento educacional especializado na educação básica, modalidade educação especial. MEC/CNE/ CDE.

Lei $N$ o 13.146, de 6 de julho de 2015. Institui a Lei Brasileira de Inclusão da Pessoa com Deficiência (Estatuto da Pessoa com Deficiência). Brasília, DF: Presidência da República.

Submetido à avaliação em 1 de março de 2015; aprovado para publicação em 25 de agosto de 2015. 